\title{
Is Blood Eosinophil Count a Predictor of Response \\ to Bronchodilators in Chronic Obstructive Pulmonary Disease? Results from Post Hoc Subgroup Analyses
}

\author{
Ahmar Iqbal $^{1} \cdot$ Neil C. Barnes ${ }^{2,3} \cdot$ Jean Brooks $^{4}$
}

Published online: 2 September 2015

(c) The Author(s) 2015. This article is published with open access at Springerlink.com

\begin{abstract}
Background Chronic obstructive pulmonary disease (COPD) patients with blood eosinophil (EOS) count $\geq 2 \%$ benefit from exacerbation reductions with inhaled corticosteroids (ICSs). We conducted post hoc analyses to determine if EOS count $\geq 2 \%$ is a marker for greater responsiveness to the bronchodilators umeclidinium (UMEC; long-acting muscarinic antagonist), vilanterol (VI; long-acting $\beta_{2}$-agonist) or UMEC/VI combination.

Methods Effects of once-daily UMEC/VI 62.5/25, UMEC 62.5 and VI $25 \mu \mathrm{g}$ versus placebo on trough forced expiratory volume in one second $\left(\mathrm{FEV}_{1}\right)$, Transition Dyspnoea Index (TDI), St George's Respiratory Questionnaire (SGRQ) scores and adverse event (AE) incidences in four completed, 6-month studies were assessed by EOS subgroup. Trough $\mathrm{FEV}_{1}$ was also evaluated by ICS
\end{abstract}

Ahmar Iqbal was employed by GSK at the time of the study.

Electronic supplementary material The online version of this article (doi:10.1007/s40261-015-0322-6) contains supplementary material, which is available to authorized users.

Neil C. Barnes

neil.c.barnes@gsk.com

1 Respiratory Franchise Medical, GSK, 5 Moore Drive, 5.3317, Research Triangle Park, NC, USA

2 Respiratory Medical Franchise, GSK, Stockley Park West, 1-3 Ironbridge Road, Uxbridge, Middlesex UB11 1BT, UK

3 The William Harvey Research Institute, Barts and The London School of Medicine and Dentistry, London, UK

4 Respiratory Medicines Development Centre, GSK, Stockley Park West, 1-3 Ironbridge Road, Uxbridge, Middlesex UB11 1BT, UK use and EOS subgroup. Analyses were performed using a repeated measures model.

Results At baseline, 2437 of 4647 (52\%) patients had EOS count $\geq 2 \%$. Overall, $\approx 50 \%$ of patients used ICSs. At day 169 , no notable variations were observed in trough $\mathrm{FEV}_{1}$ least squares mean differences between EOS subgroups versus placebo for UMEC/VI, UMEC and VI; results according to ICS use were similar. No differences were reported between EOS subgroups in TDI and SGRQ scores on day 168, or for incidences of AEs, serious AEs and AEs leading to withdrawal.

Conclusions Response to UMEC/VI, UMEC and VI in terms of trough $\mathrm{FEV}_{1}$, dyspnoea and health-related quality of life was similar for COPD patients with baseline EOS counts $\geq 2$ or $<2 \%$. EOS count did not appear to predict bronchodilator response in either ICS users or non-users.

\section{Key Points}

Response, as assessed by trough forced expiratory volume in $1 \mathrm{~s}$, dyspnoea and health-related quality of life, to treatment with once-daily umeclidinium (UMEC)/vilanterol (VI) $(62.5 / 25 \mu \mathrm{g})$, UMEC $(62.5 \mu \mathrm{g})$ or VI $(25 \mu \mathrm{g})$ was similar in chronic obstructive pulmonary disease patients with eosinophil (EOS) counts $<2$ or $\geq 2 \%$ at baseline.

EOS count does not appear to predict bronchodilator response in either inhaled corticosteroid users or non-users.

No notable differences were observed between EOS subgroups in the incidence of adverse events (AEs), serious AEs or AEs leading to withdrawal 


\section{Introduction}

Eosinophilic airway inflammation, which can increase during exacerbations, occurs in some patients with chronic obstructive pulmonary disease (COPD) [1]. It has been suggested that a biomarker for such inflammation is blood eosinophil (EOS) count [2] and that an EOS count of $\geq 2 \%$ may be associated with an increased COPD exacerbation risk [3]. This EOS cut-off may identify patients who would benefit from exacerbation reduction with inhaled corticosteroids (ICSs) [4, 5]. Pascoe et al. [5] investigated different EOS cut-offs and found $2 \%$ to be the most appropriate.

A question of interest is whether a blood EOS count of $\geq 2 \%$ is a marker of patients who are responsive not only to ICSs but also to bronchodilators. We conducted post hoc analyses to determine if EOS count $\geq 2 \%$ is a marker for greater responsiveness to bronchodilator treatment with umeclidinium [UMEC; long-acting muscarinic antagonist (LAMA)], vilanterol [VI; long-acting $\beta_{2}$ agonist (LABA)] and UMEC/VI.

\section{Methods}

Details of the four 24-week, multicentre, randomised, placebo- or active-controlled studies are published (Clinicaltrials.gov identifiers: NCT01313637, NCT01313650, NCT01316900, NCT01316913) [6-8]. Key inclusion criteria were males and females ( $\geq 40$ years) with COPD; current or former cigarette smokers $(\geq 10$ pack-year smoking history); post-salbutamol forced expiratory volume in $1 \mathrm{~s}\left(\mathrm{FEV}_{1}\right) /$ forced vital capacity $<0.7$ and predicted $\mathrm{FEV}_{1} \leq 70 \%$ of normal; and a modified Medical Research Council dyspnoea score $\geq 2$ [6-8].

In study NCT01313637, 1493 patients were randomised 3:3:3:2 to UMEC/VI 125/25 (delivering $113 / 22 \mu \mathrm{g}$ ), UMEC 125 , VI $25 \mu \mathrm{g}$ or placebo, respectively [6]. In study NCT01313650, 1532 patients were randomised 3:3:3:2 to UMEC/VI 62.5/25 $\mu \mathrm{g}$ (delivering $55 / 22 \mu \mathrm{g}$ ), UMEC 62.5 , VI $25 \mu \mathrm{g}$ or placebo, respectively [7]. In studies NCT01316900 and NCT01316913, 2332 patients were randomized 1:1:1:1 to UMEC/VI 125/25, UMEC/VI 62.5/25 $\mu \mathrm{g}$, tiotropium bromide $18 \mu \mathrm{g}$, and either VI 25 or UMEC $125 \mu \mathrm{g}$, respectively [8]. Oncedaily treatments were administered using the ELLIPTA ${ }^{\circledR}$ dry powder inhaler ${ }^{2}$ except for tiotropium (administered via the Handihaler ${ }^{\circledR}$ ).

Post hoc subgroup analyses used integrated data $(n=4713)$ from the intent-to-treat (ITT) populations in

\footnotetext{
1 The doses of UMEC used in this study (UMEC/VI 125/25 $\mu \mathrm{g}$, UMEC $125 \mu \mathrm{g}$ ) are not approved.

${ }^{2}$ ELLIPTA $^{\circledR}$ is a trademark of the GSK group of companies.
}

these studies, excluding one site due to Good Clinical Practice (GCP) violations. Subgroups were defined by EOS category ( $<2$ or $\geq 2 \%$ ) at baseline. As patients could take a concurrent stable dose of an ICS throughout these studies, additional subgroups were defined according to ICS use at screening and baseline EOS category. Trough FEV 1 (primary efficacy endpoint in each study), Transition Dyspnoea Index (TDI) focal score and St George's Respiratory Questionnaire (SGRQ) total score were analysed using a repeated measures model [terms: study, treatment, smoking status at screening, baseline or Baseline Dyspnea Index (BDI), day, geographical region, EOS subgroup, and day by baseline/BDI, day by treatment, EOS subgroup by treatment, and EOS subgroup by day by treatment interactions]. Trough $\mathrm{FEV}_{1}$ was also analysed by additional EOS subgroups of $<4$ or $\geq 4,<6$ or $\geq 6$, and $<2 \%, 2$ to $<4$, 4 to $<6$ or $\geq 6 \%$ (using the same model), and by EOS category and ICS use, using the same model but using the 4-level ICS/EOS subgroup instead of EOS subgroup. Adverse events (AEs), serious AEs (SAEs) and AEs leading to withdrawal were summarised by EOS category. Data are presented for UMEC/VI 62.5/25 and UMEC $62.5 \mu \mathrm{g}$ (both approved doses), and VI $25 \mu \mathrm{g}$.

\section{Results}

At baseline, 2210 of 4647 (48\%) and 2437 of 4647 (52\%) patients had EOS counts $<2$ and $\geq 2 \%$, respectively. Across treatments, the proportion of patients with EOS count $\geq 2 \%$ was similar (49-55\%). Approximately $50 \%$ of all patients were ICS users. The overall proportion of patients with EOS $\geq 2 \%$ was $53 \%$ (47-61\% across treatments) for ICS users, and $52 \%(49-53 \%)$ for nonICS users.

For the overall ITT populations, patient demographics and disease characteristics (Electronic Supplementary Material Table S1) for each treatment (data not shown) were well matched between EOS subgroups.

In the EOS $<2$ and $\geq 2 \%$ subgroups, trough $\mathrm{FEV}_{1}$ was statistically significantly increased by UMEC/VI, UMEC and VI versus placebo at all timepoints $(p<0.001$; Fig. 1a-c). There were no differences between the EOS $<2$ and $\geq 2 \%$ subgroups in trough $\mathrm{FEV}_{1}$ least squares (LS) mean differences from placebo for UMEC/VI, UMEC and VI treatments (Fig. 1a-c). The LS mean differences (95\% confidence interval) from placebo for EOS $<2$ versus $\geq 2 \%$, respectively, at day 169 were 197 (155-238) versus $205 \mathrm{~mL}$ (166-245) with UMEC/VI; 139 (89-189) versus $130 \mathrm{~mL}$ (83-176) with UMEC; and 109 (69-150) versus $100 \mathrm{~mL}(62-138)$ with VI. Results for EOS subgroups using different cut-offs were very similar to those using the $2 \%$ cut-off (data not shown). The trough $\mathrm{FEV}_{1}$ results with 


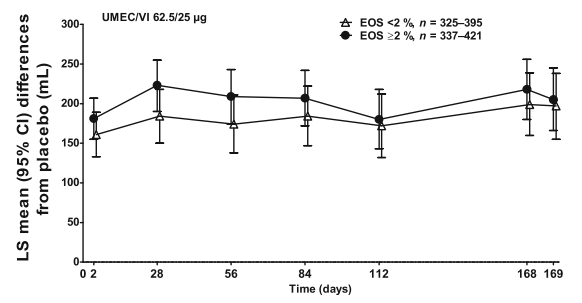

d

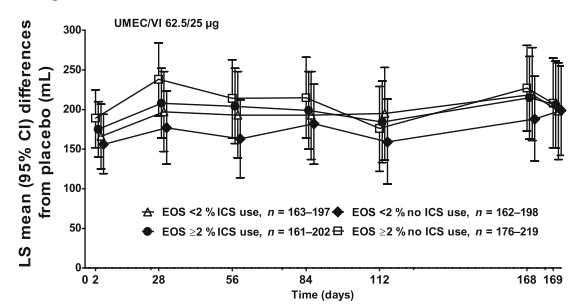

b

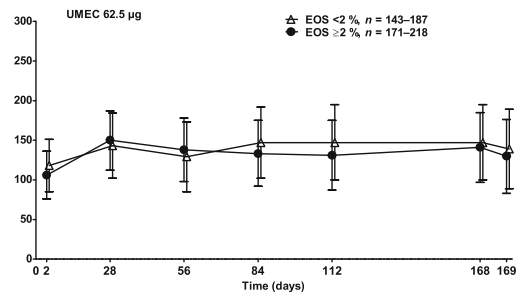

e

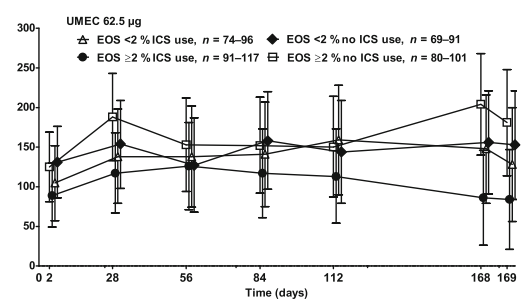

C

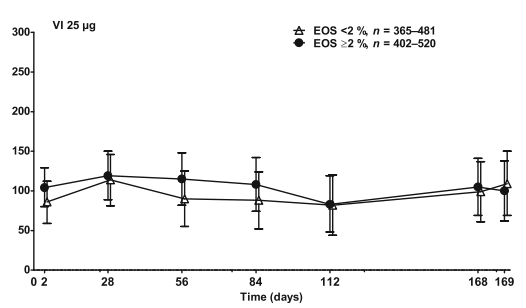

f

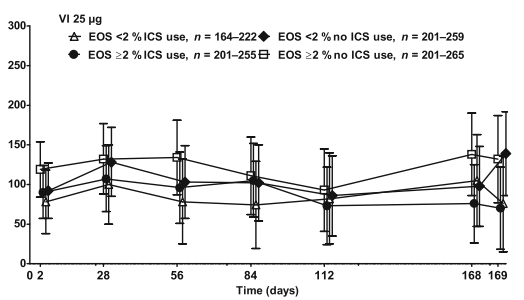

Fig. 1 Least squares mean differences from placebo in trough force expiratory volume at $1 \mathrm{~s}$ (at various timepoints) with umeclidinium/ vilanterol, umeclidinium and vilanterol treatment, by baseline eosinophil subgroup $(\mathbf{a}-\mathbf{c})$, and by baseline eosinophil subgroup and concomitant inhaled corticosteroid use (d-f). CI confidence interval, EOS eosinophil, ICS inhaled corticosteroid, $L S$ least squares, UMEC umeclidinium, $V I$ vilanterol

required to prevent COPD exacerbations [4]. With the ICS/ LABA combination of fluticasone furoate/VI, COPD exacerbations were significantly reduced by $29 \%$ $(p<0.001)$ in the EOS count $\geq 2 \%$ subgroup, but only by $10 \%(p=0.283)$ in the EOS count $<2 \%$ subgroup [5]. This is supported by the randomised, double-blind, parallel-group FORWARD (FOsteR 48-week trial to reduce exAceRbations in COPD) study, which reported that increasing blood EOS count was associated with a greater reduction in exacerbations when beclomethasone dipropionate was added to formoterol fumarate in patients with severe COPD and a history of exacerbations [9]. This differential response is perhaps unsurprising given that corticosteroids act as anti-inflammatory agents in COPD and EOS are a corticosteroid-responsive cell type [10], while, in contrast, LABAs and LAMAs act as bronchodilators via stimulation of adrenergic receptors or inhibition of muscarinic receptors, respectively [11], although LAMAs have some anti-inflammatory properties [12]. Biomarkers have great potential to improve decision making in COPD. Our results suggest that EOS will not be of value in making decisions about bronchodilator use; however, these findings need to be confirmed in prospective studies.

\section{Conclusion}

Response to UMEC/VI, UMEC and VI in terms of trough $\mathrm{FEV}_{1}$, dyspnoea and HR-QOL was similar for COPD patients with EOS counts $\geq 2$ or $<2 \%$ at baseline. EOS 
count did not appear to predict bronchodilator response in either ICS users or non-users.

Acknowledgments We thank all patients and investigators involved in these studies.

\section{Compliance with Ethical Standards}

Funding These studies and the post hoc analyses were funded by GSK. Editorial support was provided by Jackie Phillipson, PhD, at Gardiner-Caldwell Communications and was funded by GSK.

Conflict of interest $\mathrm{AI}, \mathrm{NCB}$ and JB are employees of GSK and hold stock in GSK.

Ethical approval All procedures performed in studies involving human participants were in accordance with the ethical standards of the institutional and/or national research committee and with the 1964 Helsinki Declaration and its later amendments or comparable ethical standards.

Informed consent All patients gave their written informed consent prior to the start of each study.

Open Access This article is distributed under the terms of the Creative Commons Attribution-NonCommercial 4.0 International License (http://creativecommons.org/licenses/by-nc/4.0/), which permits any noncommercial use, distribution, and reproduction in any medium, provided you give appropriate credit to the original author(s) and the source, provide a link to the Creative Commons license, and indicate if changes were made.

\section{References}

1. Saha S, Brightling CE. Eosinophilic airway inflammation in COPD. Int J Chron Obstruct Pulmon Dis. 2006;1:39-47.

2. Bafadhel M, McKenna S, Terry S, Mistry V, Reid C, Haldar P, et al. Acute exacerbations of chronic obstructive pulmonary disease: identification of biologic clusters and their biomarkers. Am J Respir Crit Care Med. 2011;184:662-71.
3. Price D, Rigazio A, Postma D, Papi A, Guy B, Agusti A, et al. Blood eosinophilia and the number of exacerbations in COPD patients [abstract]. Eur Respir J. 2014;44(Suppl. 58):4416.

4. Bafadhel M, McKenna S, Terry S, Mistry V, Pancholi M, Venge $\mathrm{P}$, et al. Blood eosinophils to direct corticosteroid treatment of exacerbations of chronic obstructive pulmonary disease: a randomized placebo-controlled trial. Am J Respir Crit Care Med. 2012;186:48-55.

5. Pascoe S, Locantore N, Dransfield MT, Barnes NC, Pavord ID. Blood eosinophil counts, exacerbations, and response to the addition of inhaled fluticasone furoate to vilanterol in patients with chronic obstructive pulmonary disease: a secondary analysis of data from two parallel randomised controlled trials. Lancet Respir Med. 2015;3(6):435-42.

6. Celli B, Crater G, Kilbride S, Mehta R, Tabberer M, Kalberg C, et al. Once-daily umeclidinium/vilanterol $125 / 25 \mathrm{mcg}$ in COPD: a randomized, controlled study. Chest. 2014;145:981-91.

7. Donohue JF, Maleki-Yazdi MR, Kilbride S, Mehta R, Kalberg C, Church A. Efficacy and safety of once-daily umeclidinium/vilanterol 62.5/25 mcg in COPD. Respir Med. 2013;107:1538-46.

8. Decramer M, Anzueto A, Kerwin E, Kaelin T, Richard N, Crater $\mathrm{G}$, et al. Efficacy and safety of umeclidinium plus vilanterol versus tiotropium, vilanterol, or umeclidinium monotherapies over 24 weeks in patients with chronic obstructive pulmonary disease: results from two multicentre, blinded, randomised controlled trials. Lancet Respir Med. 2014;2:472-86.

9. Siddiqui SH, Guasconi A, Vestbo J, Jones P, Agusti A, Paggiaro P, et al. Blood eosinophils: a biomarker of response to extrafine beclomethasone/formoterol in chronic obstructive pulmonary disease. Am J Respir Crit Care Med. 2015;192(4):523-5.

10. Jen R, Rennard SI, Sin DD. Effects of inhaled corticosteroids on airway inflammation in chronic obstructive pulmonary disease: a systematic review and meta-analysis. Int J COPD. 2012;7: 587-95.

11. Cazzola M, Page CP, Calzetta L, Matera MG. Pharmacology and therapeutics of bronchodilators. Pharmacol Rev. 2012;64: 450-504.

12. Karakiulakis G, Roth M. Muscarinic receptors and their antagonists in COPD: anti-inflammatory and antiremodeling effects. Mediat Inflamm. 2012;2012:409580. 